\title{
CONSIDERACIONES EN TORNO A LA PRESENCIA DE LA PRISIÓN EN EL TEATRO DE CALDERÓN DE LA BARCA
}

\author{
Paloma García Abad \\ Literatura Española y Teoría de la Literatura \\ Facultad de Filología \\ Apdo. Correos 60145 \\ UNED, Universidad Nacional de Educación a Distancia \\ 28080 Madrid \\ pgarcia10@educa.madrid.org \\ [Anuario calderoniano (ISSN: 1888-8046), 6, 2013, pp. 149-162] \\ El objetivo de este artículo es conocer más y mejor los recintos \\ que albergan a los personajes que son objeto de encierro en el teatro \\ de Pedro Calderón de la Barca. Nos proponemos analizar cómo son \\ dichos enclaves y por qué son así, dada la frecuencia con la que apare- \\ El punto de partida de este análisis es la constatación de dos grandes \\ prisiones que acogen, según la ideología religiosa de la época, a todos \\ los mortales, a saber, la prisión del no ser: un oscuro limbo, un alber-
} cen reflejados en su dramaturgia. gue terrible, en el que vida y muerte se confunden: 
Es el reino de la vida sin vida. La creación del Hombre queda así representada por el paso de la oscuridad de la cárcel a la luz de la libertad; y esta iluminación por la luz de la Gracia divina toma el sentido del paso de un estado moral de negación a un estado de conciencia moral de carácter positivo ${ }^{1}$.

Y la segunda es el mundo, entendido éste como cárcel del hombre. Sus calabozos sirven de morada a todo tipo de individuos sin distinción alguna:

Mundo

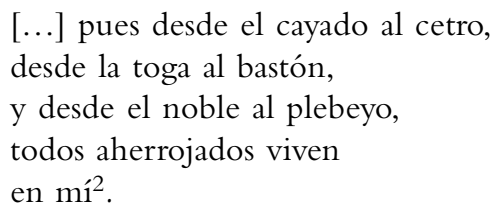

Aparte de estas dos prisiones metafóricas, que comparten el conjunto de los seres humanos, tenemos que referirnos a otros en las que se aloja a individuos concretos con una trayectoria personal singular que les lleva a ocupar temporalmente estos lóbregos emplazamientos. Con respecto a ellas, hemos constatado, primero, que cualquier lugar es susceptible de ser utilizado como prisión. La urgencia y la cercanía son los criterios que determinan esta elección. La ira al comprobar el desacato exige prontitud en el castigo. Cuando la necesidad no es tan apremiante, la elección tiene en cuenta otros criterios, como son la categoría del prisionero y los intereses del que lo ordena. Por regla general, se opta por habitáculos que están al alcance, pero lejanos. Con la cercanía se pretende un mejor control del preso y la distancia permite alejar de sí un espectáculo penoso, que avergüenza a la autoridad que lo ha decretado, puesto que la medida puede ser fruto del capricho o la irracionalidad de este último. La lejanía es una forma de castigo, en tanto que impone aislamiento a un ser que se define socialmente. Constituye además una estrategia disuasoria para aquellos que intenten penetrar en su interior con la intención de liberar a los que en ellos se consumen.

1 Parker, 1983, p. 203.

2 Calderón, El indulto general, pp. 114-115. 
No obstante lo dicho, hay castigos, como el ejemplar, que exigen la exhibición pública del detenido para escarmiento ajeno. También escapan a ese afán de ocultación las cárceles, en tanto que constituyen un espectáculo público que entretiene $\mathrm{e}^{3}$ al pueblo. Éstas se ubican en zonas urbanas y, por regla general, son dependencias que forman parte de un recinto mayor, normalmente un palacio o una fortaleza. En aquellas ciudades en las que sus puertas permanecen cerradas, negándose a los transeúntes el espectáculo visual, se invoca a otro sentido: el del oído, para que a través de éste se confirme el sufrimiento que en su interior se vive:

Fe

$$
\begin{aligned}
& \text { Aquí a su piadoso oído } \\
& \text { llegó el clamor y el gemir } \\
& \text { de los presos de la cárcel }
\end{aligned}
$$

En cuanto a la tipología que presenta el recinto punitivo en la obra calderoniana es bastante restringida: torres, calabozos, casas propias y ajenas, cárceles, conventos, grutas, castillos y cuevas.

La casa es el lugar ideal para encerrar a las mujeres que en ellas viven. En ocasiones, no se puede hablar de un encierro en sentido estricto, pero sí hay en él elementos que nos remiten al mismo: una figura masculina que decreta el aislamiento; una razón que lo justifica, y un sujeto débil que lo padece. Por supuesto, éste carece de la rigidez de una medida penal y hay puertas por las que la retenida puede entrar y salir de la misma; pero es dentro de este espacio restringido de la privacidad en el que se le imponen normas que limitan su movilidad y su libertad de acción. No obstante lo dicho, su utilización como lugar de represión no es exclusivo de este género. Hay que añadir que la vivienda particular puede ser utilizada, además, como prisión de sujetos ajenos a la misma.

De los recintos citados, hay que destacar que los palacios sirven para albergar personajes ilustres; los hay que gozan de libertad de movimiento dentro de los límites que impone el recinto palaciego y otros que ocupan dependencias más inhóspitas, como son las torres o los calabozos.

${ }^{3}$ El quehacer de los presos en la Plaza de Santa Cruz sirve de distracción a don Gil. Calderón, Entremés de la Plazuela de Santa Cruz, p. 282.

${ }^{4}$ Calderón de la Barca, La vacante general, p. 82. 
En cuanto a los prisioneros de guerra de alta alcurnia, el trato que se les dispensa está en función del estado de la negociación que se establece entre las partes en conflicto. En un principio, son agasajados como si fueran visitantes, aunque sea la suya una invitación forzosa, pero las condiciones cambian radicalmente si no se alcanza un acuerdo satisfactorio ${ }^{5}$.

Una característica que comparten todos los dramaturgos del Barroco es el escaso interés que muestran por la descripción de los lugares en los que se encierra a los personajes que sufren este lamentable destino. La mayoría de ellos se limita únicamente a concretar su ubicación y, para calificarlos, les basta un par de pinceladas que se repite de forma constante. Para cumplir con los objetivos que ellos persiguen, es suficiente con nombrarlos y, a lo sumo, localizarlos en el espacio. Los personajes que emiten las órdenes de prisión son especialmente parcos. La adjetivación se enriquece cuando cambia la perspectiva y se refieren a ellos el que sufre esta pena, alguno de sus seres queridos o simples espectadores ajenos al hecho. En cualquier caso, ésta es mínima: horrorosa, funesta, oscura, dura, estrecha son los calificativos más empleados para referirse a las cárceles en un sentido real. En un sentido metafórico, la adjetivación alude al tiempo ${ }^{6}$ (temporal y eterna) y al

${ }^{5}$ Véase el giro radical que se produce en la persona del príncipe de Portugal (ver Calderón, El príncipe constante y esclavo de su patria, p. 146):

REY:

Luego al punto

aqueste cautivo sea

igual a todos: al cuello

y a los pies le echad cadenas;

a mis caballos acuda,

y en baño y jardín, y sea

abatido como todos;

no vista ropas de seda,

sino sarga humilde y pobre;

como negro pan, y beba

agua salobre; en mazmorras

húmedas y oscuras duerma;

y a criados y a vasallos

se extienda aquesta sentencia.

${ }^{6}$ Estos dos adjetivos hacen referencia a la vida y a la muerte en el contexto alegórico en el que se desarrollan los autos. Calderón, La redención de cautivos, p. 1325. 
espacio. Las consecuencias que provoca en el individuo hacen que se la considere un lugar triste.

Normalmente los lugares elegidos son, además, de oscuros e inhóspitos, lejanos. Incluso cuando se ubican en el interior de una casa o de un palacio, se opta por las zonas más apartadas, bien en las alturas de las torres o en las profundidades de los sótanos; carentes éstos de luz e invadidos por la humedad. Separados de la tierra o en su interior. Inalcanzables, invisibles. Las cadenas, cuando las hay, impiden al detenido disfrutar de la movilidad mínima que el lugar, angosto de por sí, les posibilita. Las limitaciones tanto espaciales como lumínicas tienen como objeto situar al prisionero en la antesala de la muerte. El enclave ha de semejarse al ataúd que pasarán a ocupar en breve. $\mathrm{O}$, en las torres inexpugnables, negándoles cualquier posibilidad de salvación, de vida.

Pilar Palomo, en su análisis sobre los elementos ambientales de localización geográfica, nos apunta las causas de este aparente desinterés, que desde aquí hacemos extensible al género en su totalidad:

Creo, en definitiva, que la escasa localización costumbrista de la comedia de enredo, en el grupo que denominé palatina o palaciega, es algo más sutil que el desconocimiento. Creo que hay un afán distanciador de la realidad, un ennoblecimiento al servicio de un código aristocrático, que repele el excesivo afán referencial. Los modelos de conducta de los nobles personajes que juegan la acción amorosa, su cortesanía, su aristocracismo hay que separarlos de la realidad cotidiana, vivida, experimentada, del espectador. Lo evasivo de la acción dramática presentada, no precisa de una contextualización espacial próxima o coetánea. Incluso la recha$\mathrm{za}^{7}$.

Un género de acción, como lo es el teatro barroco, no requiere de descripciones. Cuenta con un aliado poderosísimo: el enredo, y éste tampoco necesita de ellas. Lo que prima en él es la acción y todo aquello que la fomenta y la intensifica. El enredo la nutre. Cuanto más se enmarañen y se compliquen las tramas mejor. Lo decisivo es el qué, lo que acontece. La acción gusta de la cantidad y del más dificil todavía. Por esta razón, los dramaturgos obvian las descripciones. No forman parte de sus prioridades, porque son absolutamente prescindibles.

7 Palomo, 1999, p. 202. 
Los lugares son meros contenedores de personajes que actúan enredando y enmarañando el delicado tejido de las relaciones humanas. El cómo son dichos contenedores resulta a todas luces superfluo. El enredo recurre a la prisión para dar la última vuelta de rosca. Constituye el nivel más alto de complicación al que se puede llegar; establece el momento máximo de tensión. La línea que marca el encierro es sumamente arriesgada, porque detrás de las puertas de la prisión sólo cabe encontrarse con el cadalso. El peligro de muerte es inminente. No obstante, todavía aquí es posible solucionar el conflicto, aunque las posibilidades sean mínimas. El grito ;Daos a prisión! paraliza y obliga a realizar un giro en la acción. El movimiento trepidante que ha llevado hasta aquí se detiene. Con la orden se abre un suspense. Ahora hay que seguir actuando, pero la dirección cambia. La solución sólo puede venir de otras acciones. La importancia que cobran éstas explica lo inútil de toda descripción. El mundo del teatro es el del acontecer. Hacer para deshacer.

No obstante lo dicho, Calderón de la Barca es el dramaturgo que más información nos brinda sobre las prisiones. Especialmente descriptivo se muestra este autor en el caso de aquellos presos a los que se encierra para luchar contra su propio sino, ocultándolos de las miradas ajenas. Las prisiones que éstos ocupan se sitúan en enclaves alejados, apartados y de difícil acceso. Son verdaderos laberintos. La gruta en la que se esconde a Semíramis está retirada de cualquier núcleo de población y carece de vegetación, con lo cual se intensifica la sensación de muerte. Un lugar yermo e inhóspito. Ha sido elegido cuidadosamente por ello: un ataúd para el que lo habita y un paraje poco atractivo para el visitante. La prisión de la joven, un templo dedicado a Venus, se encuentra junto a un lago. Su agua tiene propiedades adormecedoras. Al otro lado del mismo hay sólo una inmensa roca. Pero, muy a pesar de la lejanía, de lo disuasorio del paraje y del secretismo que lo rodea, la población del entorno conoce al sacerdote que custodia este templo y sabe que se esconde a alguien en su interior. Si a eso le unimos los lamentos y los aullidos que se escuchan desde dentro, el escenario del encierro se convierte en un enclave peligroso y aterrador para el que lo contempla desde fuera. El templo que oculta a Semíramis está, de alguna forma, encantado. Además de incidir en los sentidos, Tiresias ha actuado también sobre el conocimien- 
to y ha difundido una leyenda con la que persigue infundir miedo y evitar así que se descubra el sujeto del encierro. El acceso al templo es complicado, incluso para aquél a quien la leyenda no consiga disuadir del intento de acercamiento. Esta dificultad nos remite al laberinto construido por Dédalo, en el que encerró al minotauro, un monstruo mitad hombre mitad toro nacido de una pasión ilícita. El trayecto sinuoso que tiene que recorrer Menón se puede interpretar como una advertencia, por parte de la naturaleza, del peligro al que se va a ver expuesto y el tipo de personaje híbrido que lo habita.

Narciso habita, al igual que Semíramis y Aquiles, en una cueva en el monte. La diferencia es que mientras que al primero se le ha permitido ver la luz del sol, a Semíramis y a Aquiles se les ha ocultado este placer. Las cuevas se ubican siempre en lo alto de las montañas, apartadas del contacto humano y son símbolo de la ignorancia en la que viven sus moradores.

Menos agreste es la prisión donde se encierra al heredero del rey de Polonia. Ésta se sitúa igualmente en medio del campo, cerca de la corte y linda con un denso bosque. El preso se halla en el interior de una fortaleza, en la planta baja de la torre.Visto desde fuera, el edificio es tan sencillo que asemeja una roca más, desprendida de la cumbre de la montaña. Es, por lo tanto, un lugar poco atrayente para el que hasta allí llega y la idea de piedra caída nos adelanta el destino del morador de la fortaleza. Un príncipe, sumido en la desgracia que, nacido en un palacio, ha pasado a habitar una prisión:

Rosaura Rústico nace entre desnudas peñas un palacio tan breve que al sol apenas a mirar se atreve; con tan rudo artificio la arquitectura está de su edificio que parece, a las plantas de tantas rocas y de peñas tantas que al sol tocan la lumbre, peñasco que ha rodado de la cumbre ${ }^{8}$.

Frente a la gruta cerrada que oculta a Semíramis, las puertas de la torre en las que se esconde a Segismundo están entreabiertas, lo que

${ }^{8}$ Calderón, La vida es sueño, pp. 75-76. 
permite oír ruido de cadenas desde el exterior. El cautivo está encadenado y esto hace innecesario el uso de las cerraduras en las puertas de entrada. La fortaleza, vista desde fuera, denota desolación y falta de vida, y el interior remite a la noche por el dominio de la oscuridad. La prisión tiene el prodigio de igualar a los contrarios: un hombre vivo es un muerto si está encerrado.

Para interiorizar en el preso esta equiparación de vida y muerte se le priva de la luz, haciendo de su prisión un ataúd. Sólo se le permite un tenue rayo de ésta con lo que se reincide en la idea de caducidad inmediata en la que se encuentra el preso:

El espacio donde se encuentra Segismundo es muy limitado: monte y palacio: Su significado muy claro, como estudia Casalduero: el monte será el lugar de las fieras, donde permanece el hombre prisionero, el lugar del sentimiento y de la inteligencia confusos. Monte y naturaleza, agitados, serán el reflejo de su atormentado mundo interior. El palacio será el escenario del hombre en sociedad, un intento de salir de su laberinto interior a la luz, de dar sentido a su vida; esa confusión mental del hombre - fiera será trocada por otras cadenas morales. La luz le llevará al engaño y el engaño a la duda'

Tanto en el sinuoso camino que hay que recorrer para llegar al templo de Venus, en el que se oculta a Semíramis, como en el paralelismo con una roca caída, que nos ofrece la fortaleza que custodia a Segismundo, Calderón se vale de la localización para preparar al espectador antes de presentarle al personaje cuya existencia pretende mantenerse oculta: la mujer varonil y el príncipe caído en desgracia. Estos lugares, alejados y nada atrayentes a la vista, permiten, no obstante, escuchar el lamento de sus moradores y despertar la curiosidad de los ajenos al drama de sus moradores.

Climene vive su encierro en un templo situado en un monte, también de difícil acceso. Existe aquí una prohibición, cuyo quebranto se castiga con la pena de muerte, que actúa como elemento disuasorio para todos aquellos que pretendan descubrir la ocultación de la joven.

Se ha observado que cuando el que ordena el encierro alberga algún tipo de duda sobre su decisión, el régimen de prisión es más suave, y el lugar que se elige para el detenido está más cerca y es más habi-

${ }^{9}$ González Velasco, 1989, p. 21. 
table. Así, en Los dos amantes de cielo, el padre de Crisanto detiene a su hijo en su propia casa, hasta ver cómo solucionar el dilema que su visita a la cueva de los cristianos le ha planteado. El duque Carlos de Borgoña encierra a su sobrino, Enrique, en su corte para que disfrute allí de una prisión muy relajada, en De un castigo tres venganzas.

El lugar decretado para el encierro tiene una importancia fundamental en tanto que influye en el estado de ánimo del detenido. El hecho de estar preso en la casa de su amada Flor disminuye el dolor que éste supone para Federico:

Federico El mayor consuelo mío, es, señor Manfredo, verme preso en vuestra misma casa. ¡Dichoso el que en ella muere! ${ }^{10}$

El caso de las tres Hespéridas coincide con el de la joven Anajarte, reina heredera de Trinacria, en que se concreta en un lugar más acorde con su dignidad social: un palacio. No obstante, el aislamiento y la falta de libertad de movimiento hacen que los lujos no aplaquen el sufrimiento que el encierro infringe en quien lo padece:

IFIS

$$
\begin{aligned}
& \text { Porque no ignorando yo, } \\
& \text { como no lo ignora nadie, } \\
& \text { la tiranía que injusta } \\
& \text { usan Céfiro y Argante } \\
& \text { contigo (pues, prisionera, } \\
& \text { bien que entre pompas reales, } \\
& \text { en esa cárcel te tienen } \\
& \text { sin que eso al consuelo baste, } \\
& \text { pues por dorada que esté, } \\
& \text { siempre la cárcel es cárcel) }{ }^{11}
\end{aligned}
$$

Aquellos que, como el alcalde de Zalamea o el gobernador de El mágico prodigioso, obran preocupados por dar a sus acciones apariencia de equidad se ven obligados a cumplir con la normativa vigente para

${ }^{10}$ Calderón, De un castigo, tres venganzas, p. 59.

11 Calderón, La fiera, el rayo y la piedra, p. 337. 
que nada en su comportamiento exterior delate sus verdaderas intenciones.

La vivienda particular es, como ya se ha mencionado antes, el lugar ideal para encerrar a las mujeres y para que éstas se impongan un aislamiento pseudo voluntario al que siempre llegan como única solución a la que les conduce una situación asfixiante. En El mayor monstruo del mundo ${ }^{12}$, el encierro al que se somete Mariene tiene lugar en la casa en la que hasta ahora ha vivido la pareja, concretamente en una torre con jardín, cerrada con llave y con el mar por frontera. La entrada de extraños le deja a la cautiva una única salida: la ventana que da al mar. La puerta cerrada es muerte; pero una puerta abierta será igualmente mortal, ya que la infeliz amenaza con quitarse la vida si alguien se atreve a quebrantar su decisión.

Tanto Semíramis como Lidoro viven en más de una prisión. En el primer caso, hay que constatar un cierto ascenso en la categoría de prisiones que experimenta a lo largo de su vida; Semíramis pasa toda su juventud en una cueva en el templo de Venus. Luego es encarcelada en una quinta, concretamente, en una torre cerrada con llaves por el hombre que la liberó de vivir en la cueva que fue su primera morada.Y más tarde, decide ella retirarse a una zona aislada del palacio que acondiciona con rigor para hacer más dura su vida. Este continuo transitar de la joven de una prisión a otra pone de manifiesto su incapacidad para alcanzar la auténtica libertad, la del alma:

As acts of punishment or revenge or self-advancement they reflect her ambitions, ruthless and vindictive spirit, and are indict outward manifestations of that more sinister form of imprisonment to which she is condemned by personality and temperament. The circular movement of the play, beginning and ending with a battle against Lidoro, suggests that there is a pattern to the life of Semíramis from which she cannot escape. The

12 Véase la importancia que, según Arellano, tiene la idea de limitación en esta obra: «Las imágenes del laberinto y la cárcel alcanzan enorme relevancia en toda la obra y en especial en el desenlace cuando tras la persecución de Octaviano a Mariene por el cuarto del palacio, regresan al punto de partida donde ella topa con Herodes para morir a sus manos. La cárcel es un espacio omnipresente en El mayor monstruo, y menciones de calabozo, puertas cerradas, etc., se reiteran obsesivamente...» (Arellano, 2001, p. 87). 
closed structure of the play is a framework within which the many and varied prisons are part of an overall pattern ${ }^{13}$.

Por último, queremos destacar la peculiaridad que presentan los encierros que se llevan a cabo en las casas de los Justicias Mayores, en tanto que posibilitan la entrada y salida de mujeres a las habitaciones en las que se los retiene. Aunque ellos quieran ser rigurosos en el cumplimiento del aislamiento, cuentan con el conocimiento del lugar por parte de sus hijas y con la complicidad de sus criadas ${ }^{14}$.

Concluimos este artículo reiterando el carácter instrumental que hace Calderón de la Barca de cárceles y prisiones, lo que explica la escasa importancia que les conceden, en tanto que son meros receptáculos que utiliza para agravar la situación que atraviesan los personajes que aparecen en sus obras. El teatro del Barroco, género de acción por excelencia, necesita del enredo, de la confusión, de la dificultad, de los equívocos. Gusta del laberinto. Complica, lía, confunde, enreda, trastoca y después, en poco tiempo, resuelve. No le interesa la psicología de los personajes que suben a escena. No estudia las reacciones de aquellos que viven situaciones traumáticas. Tampoco se detiene en la descripción pormenorizada. Lugares e individuos se pincelan con trazos mínimos. El teatro se deleita en el simple arte de enredar para desenredar. Es más, parece, por el tiempo que le lleva, que encuentra más placer en lo primero que en lo segundo. Cual laboriosa araña, los distintos autores se esfuerzan en complicar al máximo la peripecia vital de los personajes para después volver a una situación estable de normalidad. La armonía temporalmente perdida se restituye.

13 Edwards, 1978, p. 45.

${ }^{14}$ Véase este continuo entrar y salir de Violante en la habitación en la que se encuentra detenido don Lope gracias a la colaboración de su criada Elvira (Calderón, Las tres justicias en una, p. 702):

Violante Veré

si darle un aviso puedo, ya que a mi me perdí el miedo que a sus desdichas cobré.

Quédate, Elvira, allí, porque puedas avisar, si alguno vieres entrar. 
La presencia reiterada ${ }^{15}$ del tema del encierro y las prisiones en Calderón de la Barca tiene que ver, además, con la preocupación que se detecta en este autor por la libertad:

Para Calderón la libertad es esencia constitutiva de la persona y, a la vez, fundamento de su responsabilidad. El hombre está inmerso en un acontecer personal, independiente a él y que no controla, pero, a la vez, es dueño absoluto de sus actos. Reiteradamente presenta en su teatro la libertad como centro operativo de la conducta del hombre. Sus personajes son intrínsecamente libres, aunque se vean privados de libertad fisica, y deciden y actúan por un acto de razón y de voluntad libres ${ }^{16}$.

Las prisiones, torres, calabozos, cárceles, mazmorras o las cuevas que describe Calderón son lugares inhóspitos, oscuros y angostos. En ellos no es posible vivir de forma digna, porque coartan la actuación libre del hombre. Una vida sin libertad no merece la pena ser vivida. El hombre que las habita se ve reducido a la más pura animalidad, porque se le niega la esencia del ser humano: la libertad. Ahora bien, esta libertad fisica remite a otra más profunda, la del alma. Su capacidad de obrar se ve limitada, porque su razonamiento es defectuoso, bien porque éste obra en exceso ${ }^{17}$ o bien porque es víctima de las con-

15 Suárez Miramón pone de relieve el empleo constante que este dramaturgo hace de este tema: «La cárcel es una de las imágenes más reiteradas en el teatro de Calderón, y sobre todo, en los autos, en donde expresamente define el Mundo («gran cárcel de Mundo») y el estado de ignorancia del hombre» (Suárez Miramón, 2006, p. $533)$.

16 González Velasco, 1989, p. 15.

17 Con ello nos referimos a los que Carlos Guméndez, considera una pasión desbordante de la conciencia. Según este autor, en muchos de los personajes de Calderón, la razón deja sencillamente de ser razonable, prudente o comedida y, por virtud de su ímpetu, olvida la realidad e inventa dentro de sí la idea de una totalidad absoluta. No es que los instintos paralicen la actividad razonadora del hombre, sino que, por el contrario, lo que ocurre es que esta facultad actúa en exceso; se convierte en una actividad incansable, que no cesa nunca en la búsqueda del origen de todos los fenómenos y, para ella, la tortura consiste en no encontrar jamás un último fin o causa en los que poder pensar. Parece como si la razón no se contentara con conocer y saltara por encima del entendimiento, de sus operaciones sintéticas, para unificar lo conocido. Entendido así, la razón lejos de dejar de actuar, lo que hace es excederse en su labor (ver Gurméndez, 1985). 
venciones sociales ${ }^{18}$ del momento. La vida de los «aherrojados» se sitúa próxima a la locura y, por ello, el entendimiento no tiene la capacidad de razonar con rectitud. Por otro lado, en estos espacios lúgubres se le enfrenta al hombre con la culpa. Son espacios expiatorios en los que los culpables han de sufrir por el daño que ellos han causado. El drama aumenta cuando el detenido ignora de qué se le acusa.

¡Prendedle! es el grito desesperado de quien quiere detener los acontecimientos, porque éstos le desbordan. La orden persigue la quietud, la interrupción de la acción. Pero ésta se resiste a la inmovilización.

En el teatro español del Siglo de Oro, la prisión es tratada como un medio para obtener un fin, nunca un fin en sí mismo. Su uso recurrente en la literatura de la época nos remite a la necesidad que de ella tiene un género de acción para alcanzar el clímax. En el caso concreto de Calderón, su utilización delata una preocupación profunda por lo que constituye su antítesis: la libertad.

${ }^{18}$ La lectura de la obra de Calderón no nos permite ver a un defensor a ultranza del código del honor, sino a un dramaturgo que recurre a este fenómeno para ilustrar cómo se resuelven conflictos de valores y deberes. Dicho código actúa como laberinto que confunde y dificulta el ejercicio de la libertad. Es un grillete que inmoviliza la esencia constitutiva del hombre y sólo le permite obrar en una dirección. Estamos de acuerdo con Arellano al afirmar que: «Calderón no podía defender con ningún ardor ideológico un código anticristiano que choca frontalmente con todas sus convicciones: pone en cambio de manifiesto, la tragedia de los personajes sometidos precisamente a ese código inhumana» (Arellano, 2001, p. 66). 


\section{BiBLIOGRAFÍA}

Arellano, I., Calderón y su escuela dramática, Madrid, Ediciones del Laberinto, 2001.

Calderón de la Barca, P., Obras Completas. Autos Sacramentales, vol. III, La redención de cautivos, ed. Á. Valbuena Prat, Madrid, Aguilar, 1967, pp. 13211340.

- La fiera, el rayo y la piedra, ed. A. Egido, Madrid, Cátedra, 1989.

- Entremés de la Plazuela de Santa Cruz, en Teatro cómico breve, ed. M. L. Lobato, Kassel, Reichenberger, 1989, pp. 275-285.

- Las tres justicias en una, ed. I. Benabu, Kassel, Reichenberger, 1991.

- La vida es sueño, ed. E. Rull Fernández, Madrid, Alambra, 1995.

- El indulto general, ed. I. Arellano y J. M. Escudero, Pamplona / Kassel, Universidad de Navarra / Reichenberger, 1996.

- El príncipe constante y esclavo de su patria, ed. F. Cantalapiedra y A. Rodríguez López-Vázquez, Madrid, Cátedra, 1996.

- La vacante general, ed. I. Pérez Ibáñez, Pamplona / Kassel, Universidad de Navarra / Reichenberger, 2005.

Edwards, G., The prison and the labyrinth. Studies in Calderonian Tragedy, Wales, University of Wales Press, 1978.

González Velasco, M. ${ }^{a}$ P., Variaciones de Segismundo en la obra de Calderón, Salamanca, Universidad de Salamanca, 1989.

Gurméndez, C., Tratado de las pasiones, Madrid, Fondo de Cultura Económica, Madrid, 1985.

Palomo, M. ${ }^{a}$ del P., Estudios Tirsistas, Málaga, Universidad de Málaga, 1999.

PARker, A., Los autos sacramentales del Calderón de la Barca, Barcelona, Ariel, 1983.

Suárez Miramón, A., "Los espacios nocturnos en el auto sacramental de Calderón», en La dramaturgia de Calderón: técnicas y estructuras, (Homenaje a Jesús Sepúlveda), ed. I. Arellano y E. Cancelliere, Madrid / Frankfurt, Iberoamericana / Vervuert, 2006, pp. 519-535. 